\title{
Factors affecting the properties of $\mathrm{PLA}_{\mathrm{CaSO}}$ composites: homogeneity and interactions
}

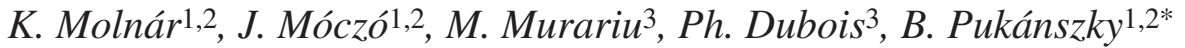 \\ ${ }^{1}$ Laboratory of Plastics and Rubber Technology, Department of Physical Chemistry and Materials Science, \\ Budapest University of Technology and Economics, H-1521 Budapest, P. O. Box 91, Hungary \\ ${ }^{2}$ Institute of Materials and Environmental Chemistry, Chemical Research Center, Hungarian Academy of Sciences, \\ H-1525 Budapest, P. O. Box 17, Hungary \\ ${ }^{3}$ Laboratory of Polymeric and Composite Materials, Center of Innovation and Research in Materials and Polymers \\ (CIRMAP), Materia Nova Research Center, University of Mons-Hainaut, Place du Parc 20, 7000 Mons, Belgium
}

Received 29 October 2008; accepted in revised form 9 December 2008

\begin{abstract}
Composites were prepared from poly(lactic acid) (PLA) and a natural $\mathrm{CaSO}_{4}$ filler to study the developed structure and the interaction of the components. The filler was characterized very thoroughly by several techniques and the results indicated that the filler contains a considerable amount of small particles with size much below the volume average size of $4.4 \mu \mathrm{m}$. The presence of these small particles did not result in inhomogeneity, considerable extent of aggregation was not observed in the composites. The filler was coated with stearic acid to modify interactions and optimum coverage corresponded to the amount estimated from the specific surface area of the filler. Mechanical properties changed only slightly with increasing amounts of the uncoated filler, but coating resulted in a drastic change of tensile properties and deformation behavior. Considerable plastic flow was observed around filler particles on the fracture surface of broken specimens. The quantitative estimation of interfacial interactions and their comparison to existing data proved that the interaction of PLA and $\mathrm{CaSO}_{4}$ corresponds to values observed in other mineral filled polymers. On the other hand, the reinforcing effect of the coated filler is extremely poor indicating almost zero interaction. Additional experiments proved that considerable amount of stearic acid dissolves in PLA and plasticizes the polymer. Stearic acid seems to desorb also from the surface of the filler, dissolve in the polymer and modify matrix properties.
\end{abstract}

Keywords: mechanical properties, $\mathrm{PLA}$ /CaSO 4 composites, surface modification, homogeneity, interfacial interaction

\section{Introduction}

Recently the interest in poly(lactic acid) (PLA) as well as in its copolymers [1-7], blends [8,9] and composites [10-21] increased enormously for various reasons. PLA has several advantages compared to fossil fuel based polymers. Among others it can be produced from renewable resources, its production consumes $\mathrm{CO}_{2}$, it is recyclable and compostable, and its properties can be modified and adjusted to a large number of applications in various ways. Increasing production capacity decreases its price thus PLA may represent a reasonable alter- native to commodity polymers in several application areas. During the purification of the lactic acid monomer considerable amount of calcium sulfate forms as a byproduct, thus it is reasonable to attempt to use this mineral filler for the modification of poly(lactic) acid. The use of this material may result in a reasonable application of the byproduct and allow the modification of PLA as well. PLA/CaSO 4 composites were reported to have advantageous properties including good strength, impact resistance and decreased price [18]. 
Recently several papers were published by some of the authors showing the advantages of $\mathrm{CaSO}_{4}$ as filler [18-22]. It was shown that the $\beta$-anhydrite II (AII) form of gypsum is thermally stable, does not absorb significant amounts of water and its use as filler in PLA results in composites with good thermal, mechanical and impact properties. The study of several $\mathrm{CaSO}_{4}$ types with different particle characteristics indicated that good homogeneity and advantageous properties can be achieved at an average particle size of $9 \mu \mathrm{m}$. The good performance of the composites was attributed to favorable interactions developing between the filler and the polymer matrix [18]. However, this relatively large particle size usually results in easy debonding especially in such stiff matrices like PLA [23]. In the paper cited above [18] the strength of interaction was estimated from the Young's modulus of composites and from tensile strength using the Nicolais-Narkis equation [24]. Unfortunately stiffness is not very sensitive to changes in interaction [25] and the Nicolais-Narkis model [24] does not include the effect of interaction, in fact it assumes complete debonding and zero load-bearing of the matrix.

Considering these open questions, the goal of our study was to shed more light onto the effect of particle characteristics and interaction on the structure and properties of PLA/CaSO 4 composites. A gypsum sample with smaller particle size (see Ref. [18]) was selected for the study, since debonding is very easy at large particle size especially in stiff matrices [23]. Interfacial interactions were estimated with the help of an appropriate model and compared to well-established materials, to PP/ $\mathrm{CaCO}_{3}$ composites extensively used in practice. Interactions were modified by coating the surface of the filler with stearic acid. Such surface modification results in a decrease of interactions which is advantageous for homogenization by decreasing aggregation, but it decreases matrix/filler interaction as well [26]. We hoped to obtain valuable information about interaction-structure-property correlations in the studied composites and to develop guidelines for the preparation of new materials with favorable properties.

\section{Experimental}

The PLA used in the experiments was obtained from NatureWorks (USA). The selected grade with
$M_{n}=88500 \mathrm{~g} / \mathrm{mol}$ and $M_{w} / M_{n}=1.8$ is recommended for extrusion. The polymer $(<2 \% \mathrm{D}$ isomer) has a density of $1.3 \mathrm{~g} / \mathrm{cm}^{3}$, while its MFI is $3.9 \mathrm{~g} / 10 \mathrm{~min}$ at $190^{\circ} \mathrm{C}$ and $2.16 \mathrm{~kg}$ load. The CAS-20-4 calcium sulfate filler was supplied by the United States Gypsum Company (USA). The filler, manufactured from high purity gypsum rock using controlled calcination and fine grinding, has a volume average particle size of $4.4 \mu \mathrm{m}$, specific gravity of $2.96 \mathrm{~g} / \mathrm{cm}^{3}$ and calcium sulfate content $>99 \%$. The $\mathrm{CaSO}_{4}$ content of the PLA composites was changed from 0 to $30 \mathrm{vol} \%$ in $5 \mathrm{vol} \%$ steps.

The filler was surface coated with various amounts of stearic acid to determine optimum coating, which corresponds to monolayer coverage [26, 27]. Coating was carried out in a Haake Rheomix 600 mixer fitted with blades for dry-blending. Coating was done at $120^{\circ} \mathrm{C}$ for $10 \mathrm{~min}$ at $100 \mathrm{rpm}$ rate with stearic acid amounts ranging from 0.1 to $5 \mathrm{~g} / 100 \mathrm{~g}$ filler in 9 steps. The surface characteristics of uncoated and coated fillers were studied by inverse gas chromatography. The fillers were aggregated in methanol, then the dried samples were grinded and sieved. The size of the grinded filler particles covered a wide range, the fraction between 400 and $800 \mu \mathrm{m}$ size was used for the filling of the column. Columns were conditioned at $140^{\circ} \mathrm{C}$ for 16 hours and measurements were done at $100^{\circ} \mathrm{C}$ with the injection of various n-alkanes. An attempt was made to determine monolayer coverage by a dissolution method developed earlier [26, 28]. DSC traces were also recorded on coated fillers; free stearic acid can be determined from the appearance of its melting peak as shown by an earlier study [29]. The particle size and particle size distribution of the filler was determined with a Malvern Mastersizer 2000, while its specific surface area with an Autosorb 1 (Quantachrome, USA) apparatus.

Poly(lactic acid) was dried at $110^{\circ} \mathrm{C}$ for 4 hours in a vacuum oven before composite preparation. Homogenization of the components was carried out at $190^{\circ} \mathrm{C}$ and $50 \mathrm{rpm}$ for $10 \mathrm{~min}$ in a Brabender W $50 \mathrm{EH}$ internal mixer attached to a Haake Rheocord EU $10 \mathrm{~V}$ driving unit. The melt was transferred to a Fontijne SRA 100 compression molding machine to produce $1 \mathrm{~mm}$ thick plates used for further testing. As a result of fast cooling with water, the plates were mostly amorphous with a negligible amount of crystalline phase (see also DSC traces later). Rheological measurements were carried out using a 
Paar Physica UDS 200 apparatus at $220^{\circ} \mathrm{C}$ in oscillatory mode in the frequency range of $0.1-6001 / \mathrm{sec}$ on discs with $25 \mathrm{~mm}$ diameter and $0.5 \mathrm{~mm}$ thickness. The amplitude of the deformation was $5 \%$. Mechanical properties were characterized by tensile testing on standard ISO 527 specimens using an Instron 5566 apparatus. Stiffness $(E)$ was determined at $0.5 \mathrm{~mm} / \mathrm{min}$ cross-head speed and $115 \mathrm{~mm}$ gauge length. Tensile strength $(\sigma)$, and elongation-at-break $(\varepsilon)$ were calculated from force vs. deformation traces measured on the same specimens at $5 \mathrm{~mm} / \mathrm{min}$ cross-head speed. The melting and crystallization characteristics of PLA and its composites were determined using a Perkin Elmer DSC 7 apparatus. Two heating and a cooling runs were done on $5 \mathrm{mg}$ samples with heating and cooling rates of $10^{\circ} \mathrm{C} / \mathrm{min}$. The particle characteristics of $\mathrm{CaSO}_{4}$ and the structure, as well as the deformation mechanism of the composites were studied by SEM (JEOL JSM-6380 LA). Micrographs were taken both from fracture surfaces created at liquid nitrogen temperature and during the failure of the specimens in the tensile testing machine. $10 \mu \mathrm{m}$ slices were cut from composites and studied by polarization optical microscopy (POM) using a Leica DFC 320 microscope to determine the distribution of the filler in the polymer and the possible presence of aggregates.

\section{Results and discussion}

The results of the study are presented in several sections. The first two deal with the particle characteristics of the filler and surface coating, two factors which are crucial for the structure of the composites and for the interactions between the components. Mechanical properties are presented next, followed by the discussion of structure and interfacial interactions in the two final sections of the paper.

\subsection{Particle characteristics of the filler}

Previous experience showed that fillers with large particle size debond very easily from the matrix $[23,30]$. Debonding results in the formation of voids that may merge into large cracks leading to the catastrophic failure of the material. Studies done on $\mathrm{PP} / \mathrm{CaCO}_{3}$ composites showed that fillers with an average particle size below $1 \mu \mathrm{m}$ strongly

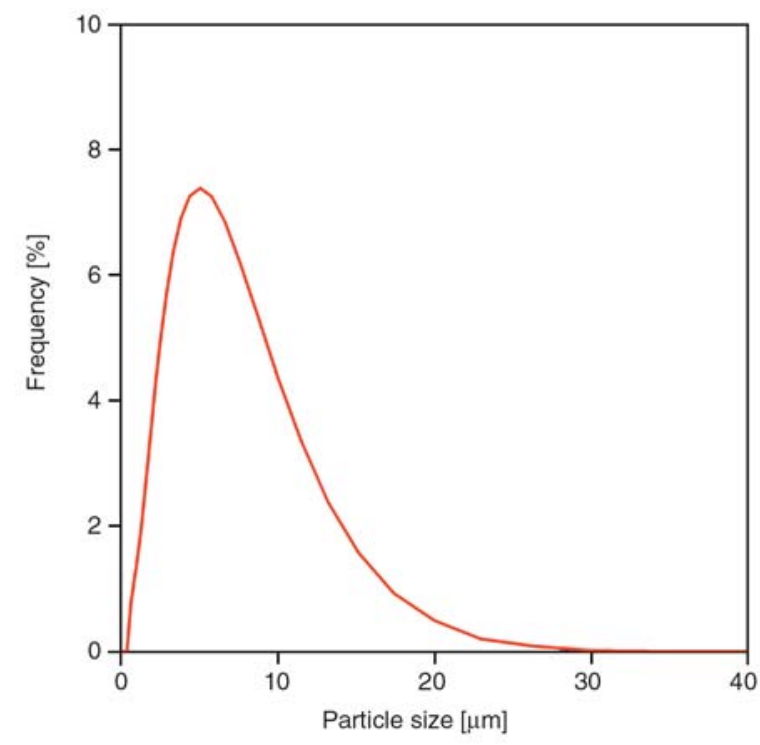

Figure 1. Particle size distribution of the $\mathrm{CaSO}_{4}$ filler used in the experiments

aggregate, and the optimum particle size in PP is around $2-3 \mu \mathrm{m}$. As a consequence, we selected a $\mathrm{CaSO}_{4}$ with a nominal median particle size of $4 \mu \mathrm{m}$ from the available assortment. However, besides average size, also the size distribution is very important for the reasons mentioned above, i.e. large particles debond very easily, while small particles aggregate. The particle size distribution of the selected filler is presented in Figure 1. Its volume average size is $4.4 \mu \mathrm{m}$, but it contains a large number of relative large particles up to $25-30 \mu \mathrm{m}$ size. Unfortunately, the presence and amount of very small particles cannot be estimated from the figure because of its scale.

Further information can be obtained about the particle characteristics of the $\mathrm{CaSO}_{4}$ filler from SEM micrographs as shown in Figure 2. The large particles are clearly visible in the micrograph, but a large number of very small particles with size below the micrometer level are also seen. These particles are attached to the larger ones and the apparatus used for particle size analysis cannot distinguish them. Small particles may aggregate deteriorating mechanical properties. Further information about particle characteristics can be deduced from the specific surface area of the filler. BET adsorption measurements yielded a specific surface area of $5.38 \mathrm{~m}^{2} / \mathrm{g}$ for our $\mathrm{CaSO}_{4}$ sample. Assuming perfectly spherical particles of uniform size, this surface area corresponds to a particle size of $0.4 \mu \mathrm{m}$. Similarly, the $4.4 \mu \mathrm{m}$ average particle size would correspond to $0.46 \mathrm{~m}^{2} / \mathrm{g}$ specific surface 


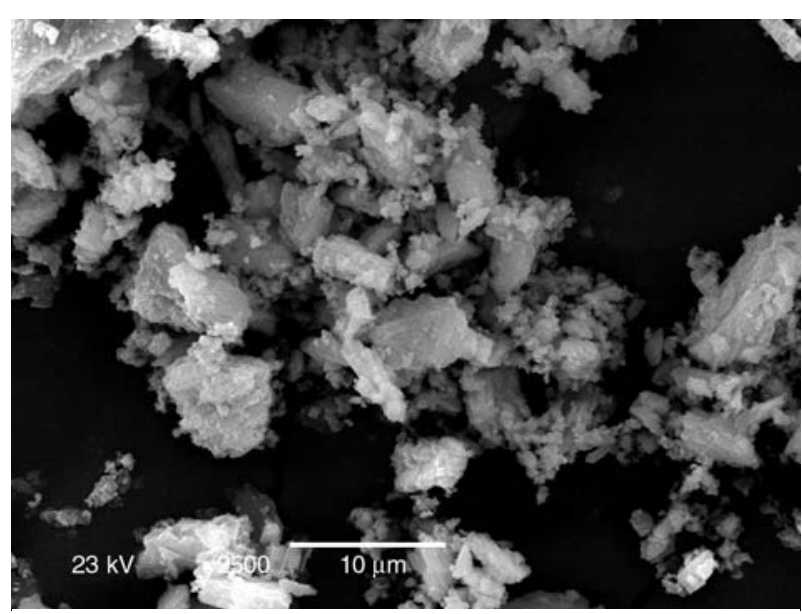

Figure 2. SEM micrograph showing the particle characteristics of the filler

area. These considerations indicate that in accordance with the SEM micrograph of Figure 2, our filler contains a large number of small particles not detected by the laser diffraction equipment. The presence of these particles might influence interactions, structure and properties of the PLA composites.

\subsection{Surface coating}

Fillers are often coated to modify interactions between the filler and the matrix polymer. Particulate fillers are usually coated with a surfactant to decrease their tendency for aggregation. Since our $\mathrm{CaSO}_{4}$ filler contains small particles, such a surface modification is assumed to be beneficial also in our case. The first choice is stearic acid for this purpose, since similarly to $\mathrm{CaCO}_{3}$, it may react chemically with the surface offering efficient coating [26]. Optimum surface coverage depends on the specific surface area of the filler, as well as on the surface need and orientation of the molecules on the surface of the particles. The optimum amount of surfactant proved to be close to monolayer coverage $[26,28]$. A simple way to determine the adsorption of the surfactant on the filler is offered by the dissolution method [26, 31]. The filler is coated with increasing amounts of surfactant, the coated filler is washed with a solvent and the irreversibly bonded surfactant is determined by an appropriate analytical technique (IR, UV, etc.). The method principally results in an adsorption isotherm (for further details see Ref. [31]). The adsorption of stearic acid on the surface of our $\mathrm{CaSO}_{4}$ is shown in

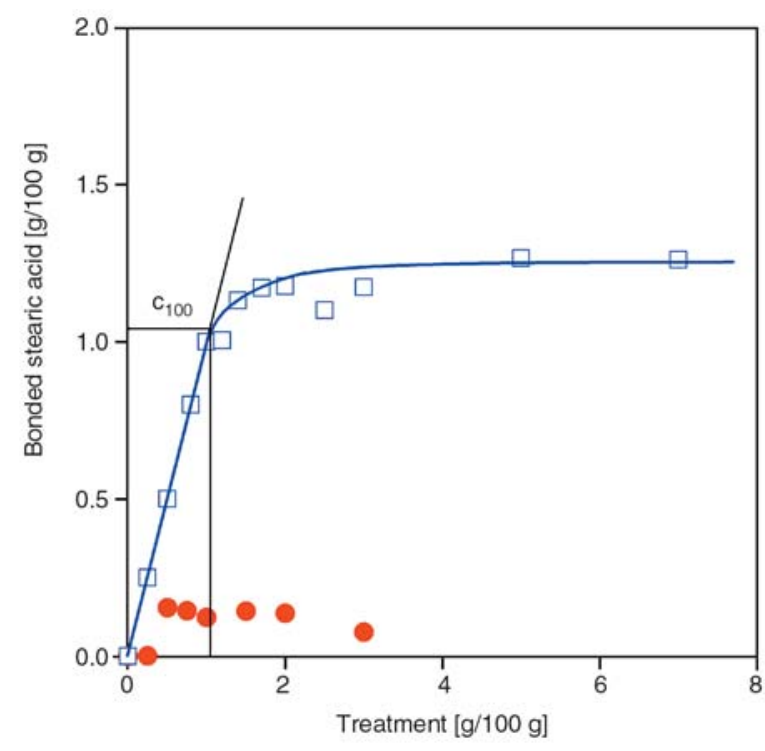

Figure 3. Adsorption of stearic acid on the surface of $\mathrm{CaSO}_{4}(\bullet)$ and on $\mathrm{CaCO}_{3}(\square)$ shown as reference. The dissolution curves were determined in $\mathrm{CHCl}_{3}$

Figure 3. A dissolution curve recorded on $\mathrm{CaCO}_{3}$ is included as comparison. The latter presents a typical example, adsorption goes to saturation and monolayer coverage is very close to the amount where the isotherm deviates from linearity (indicated in the figure by $c_{100}$ ). Contrary to the very nice adsorption isotherm obtained for $\mathrm{CaCO}_{3}$, the one determined for $\mathrm{CaSO}_{4}$ is very difficult to interpret. Almost no stearic acid is bonded onto the surface, which contradicts our expectations, but does not agree with the relatively large specific surface area of the filler either. Small particles indicated by model calculations and also by the SEM micrograph of Figure 2 do not settle in the suspension and bias the determination of the concentration of stearic acid by FTIR spectroscopy.

The fillers coated with different amounts of stearic acid were studied also by DSC. Free stearic acid crystallizes on the surface of the filler and the melting peak of the surfactant can be detected on the traces [29]. According to this method monolayer coverage is around $1.0-1.5 \mathrm{~g}$ stearic acid/100 g filler. Monolayer coating can be determined also from the change of surface tension with coverage. Surface tension decreases quite steeply with increasing coverage to a minimum, than slightly increases as a double layer of surfactant forms on the surface of the filler [29, 32]. The dispersion component of the surface tension of the filler is 


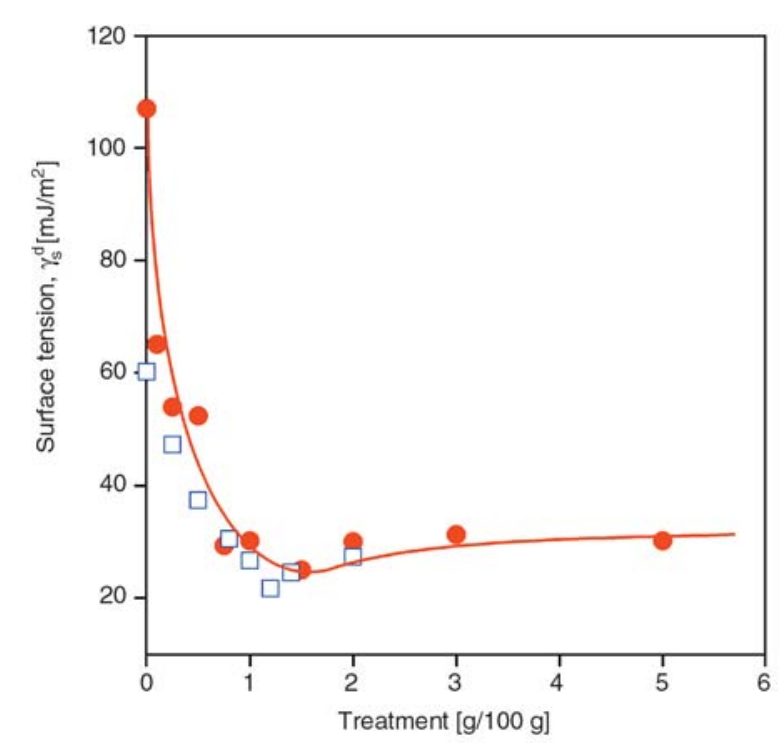

Figure 4. Change of the dispersion component of surface tension $\left(\gamma_{s}^{d}\right)$ with the amount of stearic acid used for treatment; $(\bullet) \mathrm{CaSO}_{4},(\square) \mathrm{CaCO}_{3}$

plotted against surface coverage in Figure 4. $\mathrm{A} \mathrm{CaCO}_{3}$ filler is used for comparison again. The dependence of surface tension on coverage is very similar for the two fillers. Moreover, the final value of surface tension is practically the same in both cases. Even the location of the minimum corresponds to the prediction, the $\mathrm{CaCO}_{3}$ filler used had a specific surface area of $4.0 \mathrm{~m}^{2} / \mathrm{g}$, i.e. the minimum should be located at slightly smaller stearic acid content than for the $\mathrm{CaSO}_{4}$ studied. According to these measurements, optimum coating is in the range of 1.0-1.5 g stearic acid/100 $\mathrm{g} \mathrm{CaSO}_{4}$ filler.

A further check of the amount of optimum coating is offered by the relationship between the specific surface area of the filler and monolayer coverage. Using previous data obtained on $\mathrm{CaCO}_{3}$ fillers with different specific surface area offers us the possibility to check the results of DSC and IGC measurements presented in the previous paragraph. The relationship is plotted in Figure 5. A perfectly linear correlation was obtained in previous studies; data for all the fillers fit the line reasonably. The $1.5 \mathrm{~g}$ stearic acid/100 $\mathrm{g} \mathrm{CaSO}_{4}$ coverage determined by two methods also fits the correlation reasonably well. The figure and the other results presented in this section allow us to draw several conclusions. The specific surface area determined by BET adsorption is correct and the filler contains a large number of small particles as indicated by SEM micrographs. $\mathrm{CaSO}_{4}$ can be covered with stearic acid, which decreases its surface tension

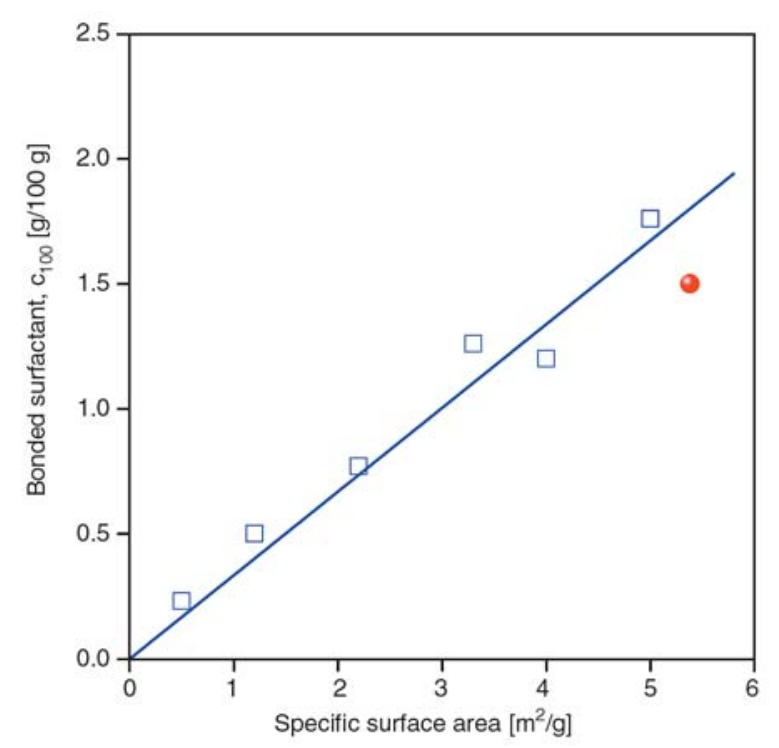

Figure 5. Correlation between the amount of stearic acid needed for monolayer coverage and the specific surface area of the filler; $(\bullet) \mathrm{CaSO}_{4},(\square) \mathrm{CaCO}_{3}$

considerably. Accordingly, some aggregation may be expected in composites containing the uncoated filler, but less in those prepared with the surface modified $\mathrm{CaSO}_{4}$.

\subsection{Mechanical properties, failure}

The modulus of particulate filled composites does not offer much information about structure and interactions. Modulus depends on the orientation of anisotropic particles, but it is influenced by specific surface area or the strength of interaction only slightly, and by aggregation practically not at all $[33,34]$. Properties measured at larger deformations, i.e. tensile yield stress and tensile strength, as well as the corresponding deformations depend strongly on structure and interaction. This is demonstrated by Figure 6, in which the tensile strength of PLA/CaSO 4 composites is plotted as a function of filler content both for uncoated and coated gypsum. Strength decreases with increasing filler content in both cases, but the rate of decrease differs considerably. The decrease for the uncoated filler is moderate in accordance with previous results [18]. This indicates reasonable interaction of the filler with the matrix polymer. However, the dominating deformation process is the separation of the phases at the interface, i.e. debonding, which occurs in most particulate filled composites. Surface coating leads to a significant decrease in strength. The difference in the effect of the coated 


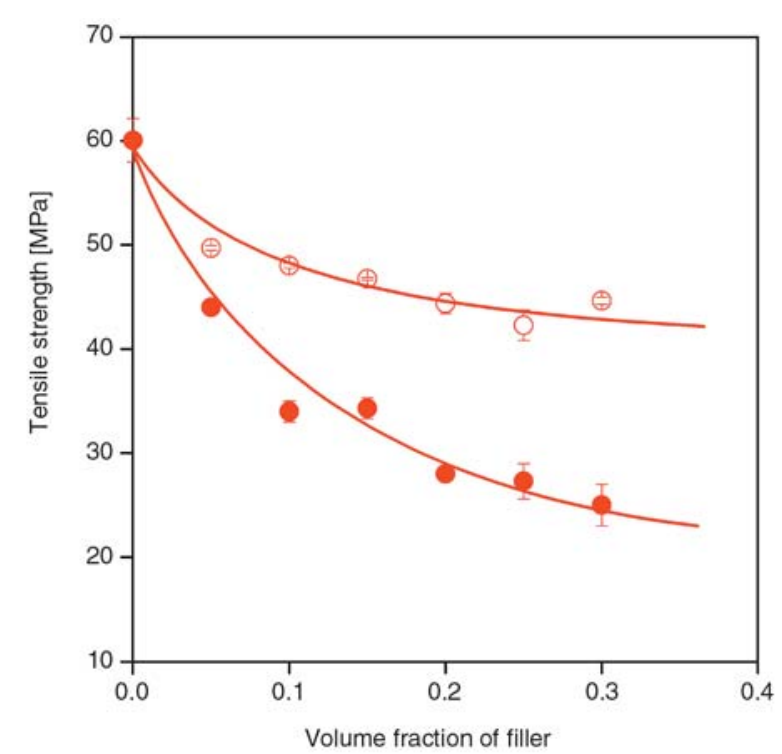

Figure 6. Composition dependence of the tensile strength of PLA/CaSO 4 composites. Effect of surface coating; $(\mathrm{O})$ uncoated, $(\bullet)$ coated filler

and uncoated filler on strength indicates that surface coating was effective and all interactions decreased in the composites. As a consequence, we may expect better dispersion in composites containing the coated filler.

The composition dependence of the corresponding deformation is presented in Figure 7. Elongationat-break is very small for the composites prepared with the uncoated filler; the composites fail by brittle fracture. The increase of filler content results in the continuous decrease of ultimate deformation. On the other hand, surface coating increases deformability somewhat, although the elongationat-break values remain quite small. Nevertheless, we can see the effect of decreased interaction. We

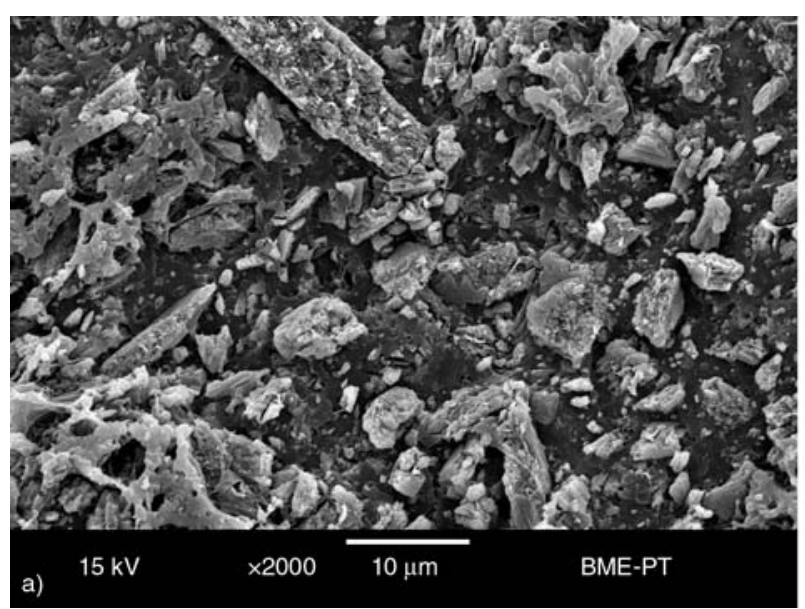

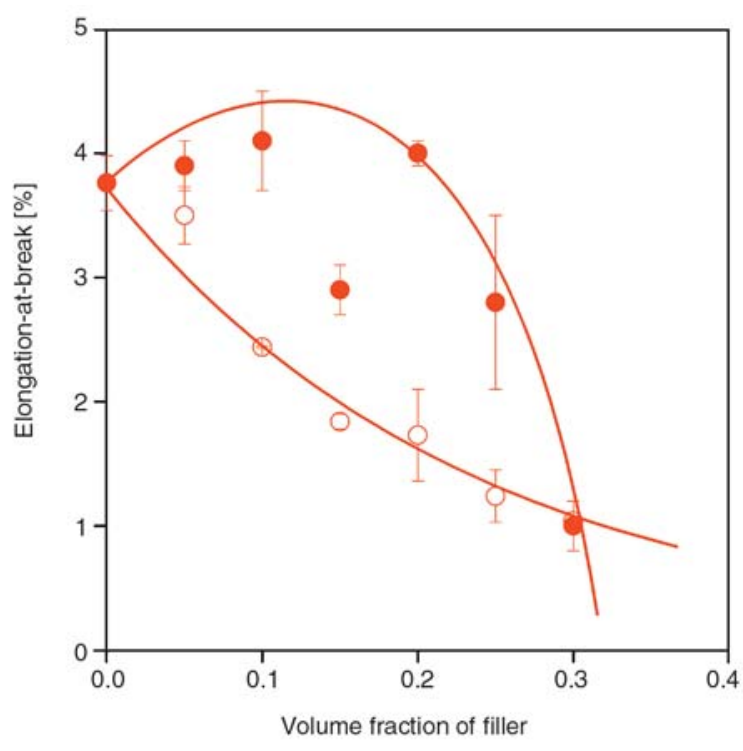

Figure 7. Effect of filler content and coating on the ultimate deformation of $\mathrm{PLA} / \mathrm{CaSO}_{4}$ composites;

(O) uncoated, $(\bullet)$ coated filler

may assume that debonding becomes easier as an effect of surface coating, even small particles debond and ultimate deformation increases somewhat.

The effect of coating is reflected also in the failure of the composites. Figure $8 \mathrm{a}$ presents the fracture surface generated by the tensile testing of a PLA composite containing $25 \mathrm{vol} \%$ uncoated filler. Brittle failure is clearly shown by the micrograph and the adhesion of the phases seems to be moderate, the clean surface of a large number of particles is seen. The micrograph also indicates that stress concentration around the particles initiates debonding, the separation of the phases changes stress distribution and leads to the failure of the specimen. On the

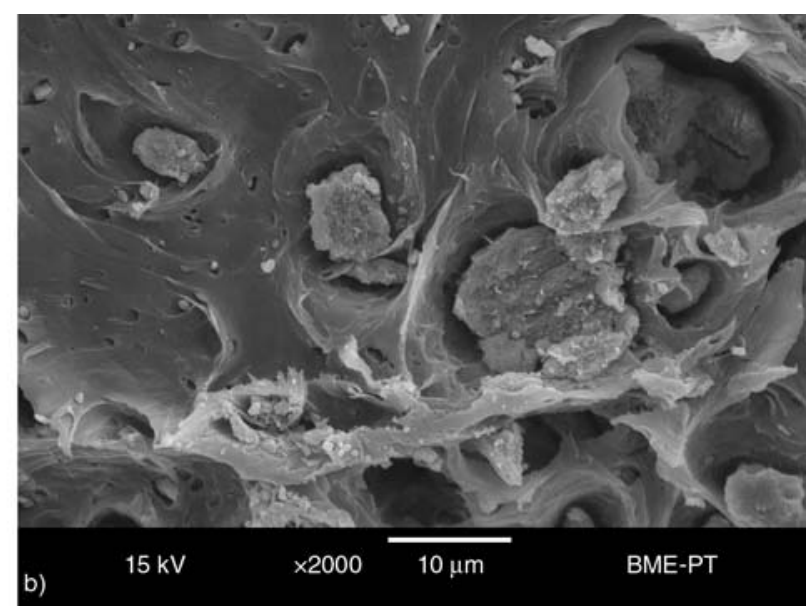

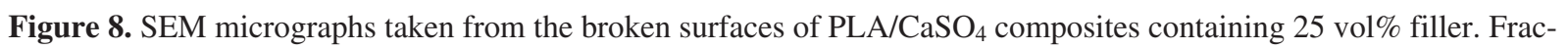
ture surfaces were created during tensile testing. a) uncoated, b) coated. See considerable plastic flow in the latter case. 
other hand, the fracture surface of the composite containing the coated filler is quite surprising (Figure $8 \mathrm{~b}$ ). Large holes can be observed around larger particles showing not only debonding, but also considerable plastic flow as well. Obviously this latter causes the increase in deformability observed in Figure 7. Surface coating alone does not justify such a drastic change in the deformation behavior of the composite. The micrograph indicates a change in matrix properties, which might be caused by the stearic acid treatment. However, SEM micrographs cannot supply any proof for such a hypothesis thus we refrain from further speculation here.

\subsection{Structure}

The morphology of $\mathrm{PLA} / \mathrm{CaSO}_{4}$ composites is relatively complicated. The polymer can crystallize, but the rate of crystallization is rather slow thus under the conditions of normal processing operations it remains mostly amorphous; its crystalline content is very small. Besides crystalline structure, the distribution of the filler in the matrix, i.e. the possible formation of aggregates is also an important issue. The filler might influence also interphase formation and the mobility of the polymer molecules. In order to obtain a better insight into these

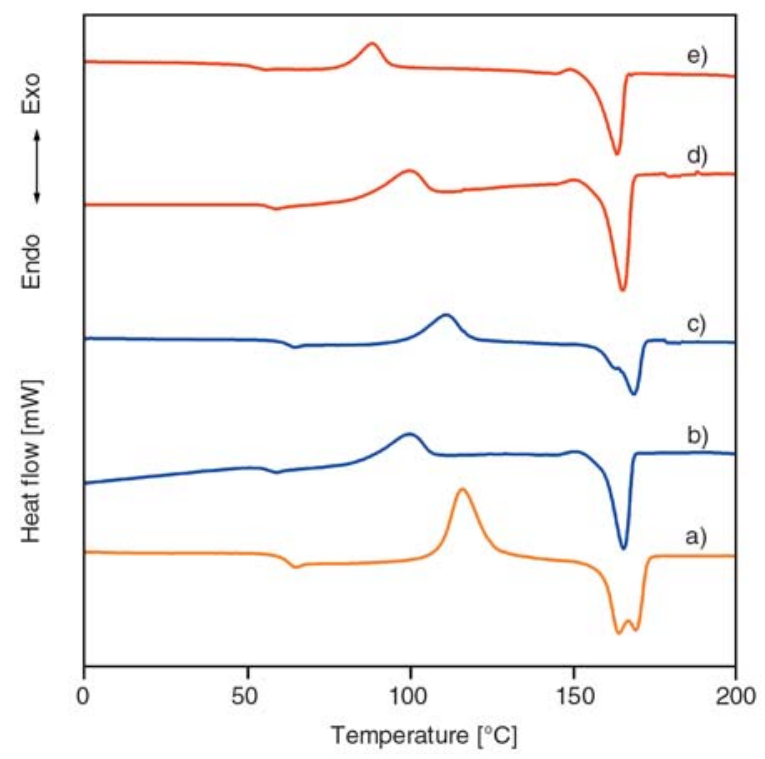

Figure 9. DSC traces recorded in the second melting run on PLA and PLA/CaSO 4 composites with various filler content; a) PLA, b) 10 vol\%, uncoated, c) $25 \mathrm{vol} \%$ uncoated, d) $10 \mathrm{vol} \%$, coated, e) 25 vol\%, coated filler questions, DSC measurements and microscopy were carried on the composites.

The DSC traces recorded during the second heating of PLA and some composites are presented in Figure 9. The traces are rather complicated showing several transitions. The glass transition temperature of the amorphous phase of PLA is clearly detected at around $60^{\circ} \mathrm{C}$. This is followed by the peak of cold crystallization and then the melting of the crystalline polymer. Melting occurs in two steps, which indicates the recrystallization of PLA, the perfection of the crystals during heating. The crystallization and melting behavior of PLA is known; the possible effect of the filler and surface coating is more interesting for us. Based on the figure two observations can be made. The $T_{g}$ of the polymer shifts to lower temperatures both in the presence of the uncoated and the coated filler. The double peak of melting also changes and transforms to a single process with increasing filler content. The temperature of the peak shifts towards lower temperatures. The composition dependence of $T_{g}$ is plotted in Figure 10. The significant shift in the glass transition temperature is rather surprising especially for the uncoated filler. Usually no change can be observed in the $T_{g}$ of particulate filled polymers, or some increase is expected at very large specific surface areas due to the formation of a hard interphase. Weak interaction may lead to an increase in the mobility of the segments, but not in the extent

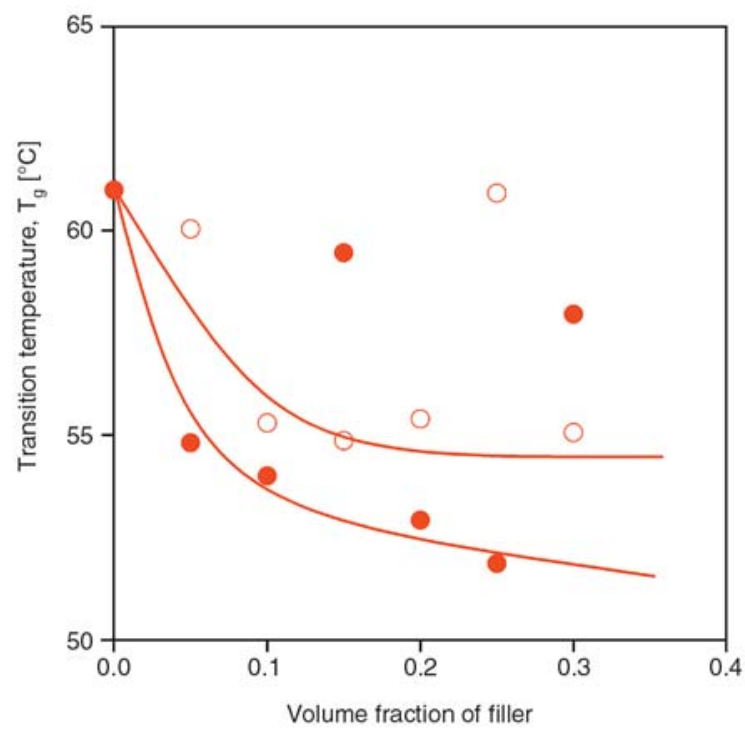

Figure 10. Decrease in the glass transition temperature of PLA with increasing filler content in PLA/ $\mathrm{CaSO}_{4}$ composites; (O) uncoated, $(\bullet)$ coated filler 
observed in the figure. This increase in mobility is very difficult to explain and needs further study. On the other hand, the change in the melting behavior might be explained with the increased mobility. Cold crystallization proceeds easier if the chains are more mobile and recrystallization does not occur during melting. It is also worth to note, that several points deviate from the general tendency in the figure. This is observed in most properties (see also Figure 7) and also needs further investigation and explanation.

The dispersion of the filler particles was studied by microscopic techniques and by rheology. Rather surprisingly significant aggregation was not observed by any method. The SEM micrographs in Figure 8 indicate the homogeneous distribution of the particles. The same result was obtained by polarization optical microscopy. Large particles were clearly visible in the micrographs, but aggregates of 50-100 micron large often observed in composites prepared from $\mathrm{CaCO}_{3}$ [35] could not be detected in any of them. Oscillatory rheometry is a very sensitive tool to detect aggregation. The ColeCole representation of the components of dynamic viscosity clearly shows the presence of a relaxation process with a different, longer relaxation time assigned to the formation of aggregates [34]. ColeCole plots and the calculation of average relaxation time indicated a very small degree of aggregation only at $30 \mathrm{vol} \%$ filler content. In view of the large specific surface area and the large number of small particles (see Figure 2) the lack of aggregation is rather surprising. Since the surface energy of $\mathrm{CaSO}_{4}$ is rather large (see Figure 4), the only reasonable explanation is that small particles remain attached to the surface of larger ones even after processing, on the one hand, and they are easily dispersed after coating, on the other.

\subsection{Interfacial adhesion}

The effect of interactions can be estimated from properties determined at large deformations, like tensile yield stress or tensile strength, with the use of appropriate models. A simple model developed earlier [36-38] takes into account the influence of the decreasing load-bearing cross-section of the polymer due to filling, while the effect of interaction is expressed by an exponential term, i.e. (Equation (1)):

$$
\sigma_{T}=\sigma_{T_{0}} \lambda^{n} \frac{1-\varphi}{1+2.5 \varphi} \exp (B \varphi)
$$

where $\sigma_{T}$ and $\sigma_{T_{0}}$ are the true tensile strength $\left(\sigma_{T}=\right.$ $\sigma \lambda$ and $\lambda=L / L_{0}$ ) of the composite and the matrix, respectively, $n$ is a parameter expressing the strain hardening tendency of the matrix, $\varphi$ is the volume fraction of the filler and $B$ is related to its relative load-bearing capacity, i.e. to the extent of reinforcement, which depends on interfacial interaction. The relationship of $B$ to the size of the interface and the properties of the interphase are expressed by Equation (2):

$$
B=\left(1+A_{f} \rho_{f} \ell\right) \ln \frac{\sigma_{T_{i}}}{\sigma_{T_{0}}}
$$

where $A_{f}$ and $\rho_{f}$ are the specific surface area and density of the filler, while $\ell$ and $\sigma_{T_{i}}$ the thickness and strength of the interphase. We can write Equation (1) in linear form (Equation (3)):

$\ln \sigma_{T_{\text {red }}}=\ln \frac{\sigma_{T}(1+2.5 \varphi)}{\lambda^{n}(1-\varphi)}=\ln \sigma_{T_{0}}+B \varphi$

and plotting the natural logarithm of the reduced tensile strength of the composite against filler content should result in a linear correlation, the slope of which is proportional to the reinforcing effect of the filler.

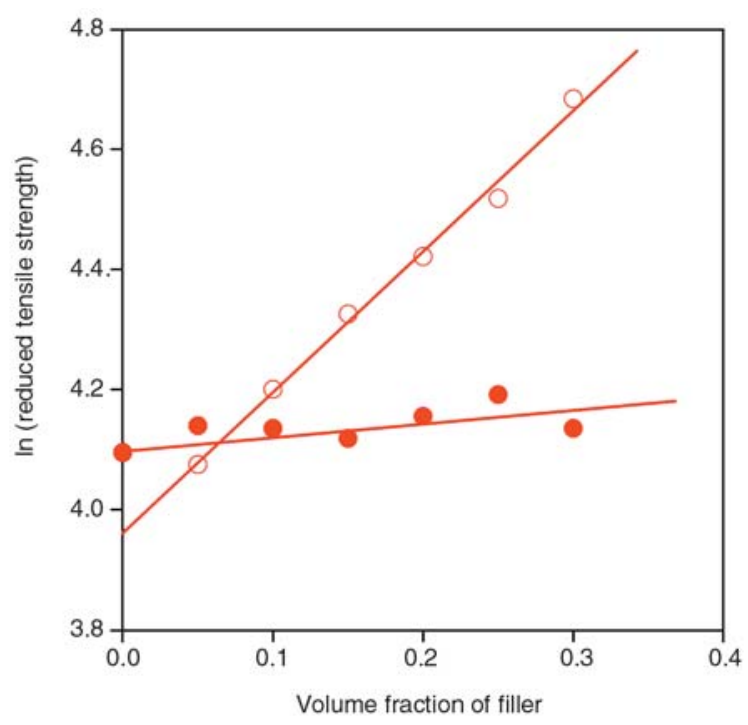

Figure 11. Quantitative determination of matrix/filler interaction in $\mathrm{PLA} / \mathrm{CaSO}_{4}$ composites. The tensile strength of the composites is plotted against composition in the representation of Equation (3); (O) uncoated, $(\bullet)$ coated filler 
The reduced tensile strength of the studied composites is plotted in Figure 11 in the form indicated by Equation (3). We obtain straight lines in both cases indicating good dispersion and the absence of structural effects. This confirms our conclusions about structure drawn in the previous section. The intersection of the line obtained for the composites containing the uncoated filler differs slightly from the value determined for the matrix polymer. This can be the result of erroneous measurement or the effect of changing polymer properties in the presence of the filler. This latter seems to cause the difference in our case since the line obtained with the coated filler intersects the axis at the value of the matrix. The slope of the line is 2.33 for the uncoated filler indicating relatively strong interaction. According to Equation (2), the reinforcing effect, i.e. parameter $B$, depends also on the strength of the matrix, which is quite high for PLA. On the other hand, the load-bearing capacity of the coated filler is close to zero, we obtained 0.17 for parameter $B$. This again proves the drastic decrease of interaction (see Figure 4) and justifies the change in deformation mechanism (see Figure 8b).

We can clearly see the difference in reinforcing effect and interaction in the two composites containing the uncoated and coated filler, respectively, but do not know how these values relate to other polymer/filler pairs. $B$ parameters obtained for $\mathrm{PP} / \mathrm{CaCO}_{3}$ composites are plotted against the spe-

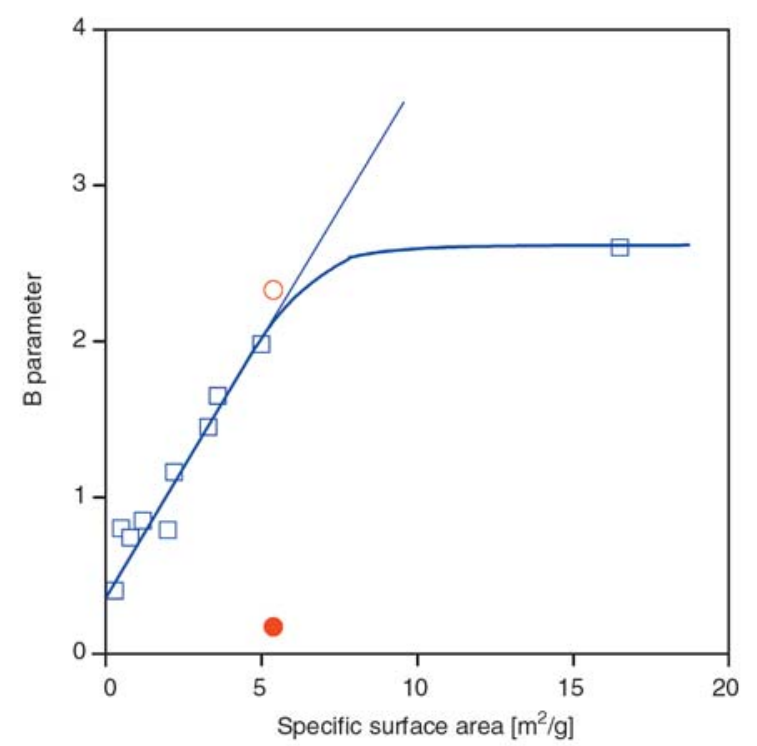

Figure 12. Dependence of parameter B on the specific surface area of the filler; (O) uncoated $\mathrm{CaSO}_{4}$, $(\bullet)$ coated $\mathrm{CaSO}_{4},(\square) \mathrm{CaCO}_{3}$ used as reference cific surface area of the filler in Figure 12 for comparison. Equation (2) indicates that if the thickness and properties of the interphase are the same for all composites prepared from the same matrix, $B$ should depend linearly on specific surface area, i.e. (Equation (4)):

$$
B=k_{1}+k_{2} A_{f}
$$

where $k_{1}=\ln \left(\sigma_{T_{i}} / \sigma_{T_{0}}\right)$ and $k_{2}=k_{1} \rho_{f} \ell$. The first part of the correlation, below $6 \mathrm{~m}^{2} / \mathrm{g}$ surface area, corresponds to the prediction of Equation (4), but deviates at larger $A_{f}$ values. The deviation is caused by the aggregation of the filler, which results in smaller interfacial area than calculated from the specific surface area and the amount of filler. The $B$ value obtained for the $\mathrm{PLA} / \mathrm{CaSO}_{4}$ composite fits the correlation perfectly, which is rather surprising, since matrix properties are different from those of $\mathrm{PP}$, but the surface tension of the filler is also larger which should lead to dissimilar interphase characteristics $[39,40]$. Nevertheless, we can conclude from these results that the strength of interaction in the $\mathrm{PLA} / \mathrm{CaSO}_{4}$ composites is in the same range usual for particulate filled composites containing uncoated mineral fillers. Surface modification results in a drastic decrease of interaction, which is much stronger than expected and very difficult to explain. To develop some idea about the magnitude of this decrease, the $B$ value of 1.98 obtained for coated $\mathrm{CaCO}_{3}$ with $5.0 \mathrm{~m}^{2} / \mathrm{g}$ specific surface area $\left(A_{f}\right)$ in PMMA matrix with tensile strength $\left(\sigma_{m}\right)$ of $54.9 \mathrm{MPa}$ must be compared to the $B=0.17$ at $A_{f}=5.38$ and $\sigma_{m}=60 \mathrm{MPa}$ for the PLA/CaSO 4 composite.

Rheology supplies a further proof for the extraordinary effect of the coated filler on composite properties. The relative complex viscosity of the composites measured at $220^{\circ} \mathrm{C}$ and $10 \mathrm{~s}^{-1}$ frequency is plotted against filler content in Figure 13. The viscosity of the melt increases with filler content in the presence of the uncoated filler, but it decreases continuously with increasing amount of the coated filler. This is rather surprising and against the prediction of all models even if the interaction is decreased considerably due to coating with stearic acid.

In order to shed more light onto the phenomenon and clarify the role of stearic acid, PLA blends were prepared with various amounts of the surfactant. The point indicated by $(\star)$ was obtained for a 


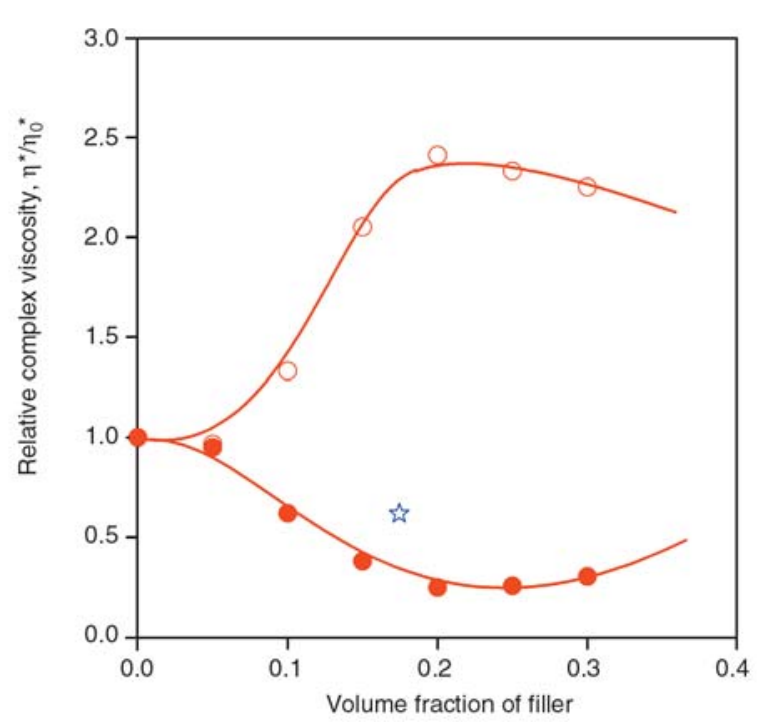

Figure 13. Composition dependence of the complex viscosity of $\mathrm{PLA} / \mathrm{CaSO}_{4}$ composites determined at $10 \mathrm{~s}^{-1}$ frequency and $220^{\circ} \mathrm{C}$; (O) uncoated, $(\bullet)$ coated filler, $(\star) 0.5 \mathrm{wt} \%$ stearic acid

blend, which contains the same amount of stearic acid $(0.5 \mathrm{wt} \%)$ as on the surface of the coated filler at $17.5 \mathrm{vol} \%$ filler content. The point fits perfectly the general correlation indicating a lubricating or plasticizing effect of the stearic acid in PLA. We may assume that the active hydrogen atom of the acid forms strong H-bridges with the carbonyl oxygen of the polymer. The measurement of the transparency of plates compression molded from the blends indicates a solubility of about $1 \mathrm{wt} \%$ of stearic acid in PLA. Only the question remains whether the PLA/stearic acid interaction is strong enough to dissolve also the surfactant adsorbed on the surface of the filler or only surplus surfactant plasticizes PLA.

To check the hypothesis of lubrication or plasticization further we carried out also the thermal analysis of the blends. DSC traces recorded during the second heating of the samples are presented in Figure 14. Practically all transitions shift towards lower temperatures including glass transition, cold crystallization and melting. The very pronounced double melting peak caused by crystal perfection disappears and the polymer melts in one step probably due to the larger mobility of the chains. The very strong plasticizing effect of stearic acid is clearly shown by the change of $T_{g}$ with composition (Figure 15). The decrease of the glass transition temperature by $5^{\circ} \mathrm{C}$ upon the addition of only $2 \mathrm{wt} \%$ stearic acid is very drastic indeed. From

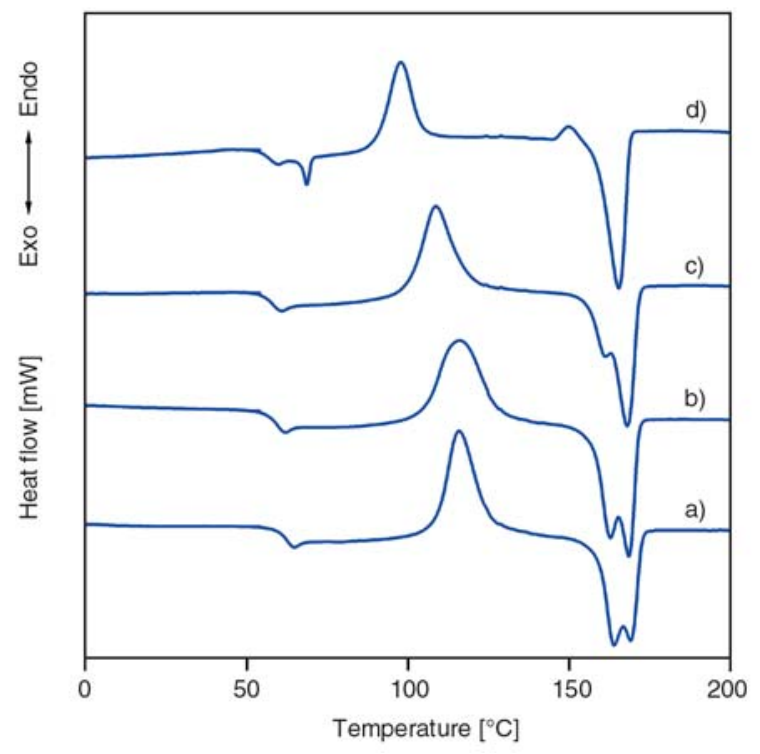

Figure 14. DSC traces recorded on PLA/stearic acid blends in the second heating run; a) PLA, b) $0.5 \mathrm{~g}, \mathrm{c}) 1.0 \mathrm{~g}, \mathrm{~d}) 2.0 \mathrm{~g}$ stearic acid

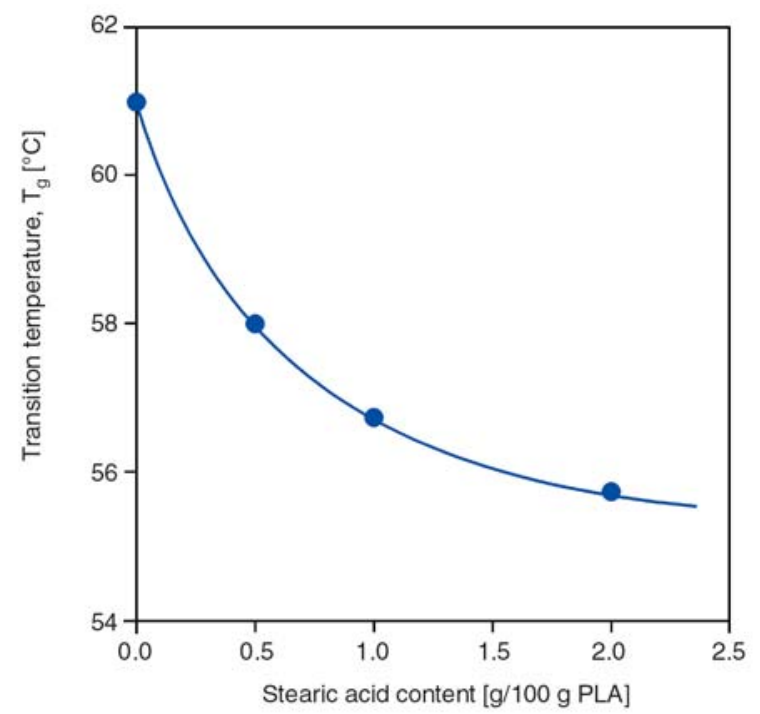

Figure 15. Effect of the amount of stearic acid on the glass transition temperature of PLA

these experiments we may conclude that stearic acid must be used with care for the surface modification of fillers added to PLA, since it interacts strongly with the polymer. The presence of large amounts of excess stearic acid may result in decreased tensile strength, but also in a decrease of molecular weight due to acid catalyzed hydrolytic cleavage [18].

\section{Conclusions}

The $\mathrm{CaSO}_{4}$ filler used for the preparation of PLA composites was characterized very thoroughly by 
several techniques and the results indicated that the filler contains a considerable amount of small particles. In spite of the expectations, the presence of these small particles did not result in inhomogeneity, considerable extent of aggregation was not observed in the composites. The filler was coated with stearic acid to modify interactions and optimum coverage corresponded to the amount estimated from the specific surface area of the filler. Mechanical properties changed only slightly with increasing amounts of the uncoated filler, but coating resulted in a drastic change of properties and deformation behavior. Considerable plastic flow was observed around filler particles on the fracture surface of broken specimens. The quantitative estimation of interfacial interactions and their comparison to existing data proved that the interaction of PLA and $\mathrm{CaSO}_{4}$ corresponds to values observed in other mineral filled polymers. On the other hand, the reinforcing effect of the coated filler is extremely poor indicating almost zero interaction. Supplementary experiments proved that considerable amount of stearic acid dissolves in PLA and plasticizes the polymer. Stearic acid seems to desorb also from the surface of the filler and dissolve in the polymer. Further study is needed to explain certain phenomena (large deviations in measured values, the decrease of $T_{g}$ in the presence of the uncoated filler, cold crystallization and melting, etc.) and to find the best surface coating agent for the application.

\section{Acknowledgements}

The authors are indebted to Szilvia Klébert, Károly Renner and Alfréd Menyhárd for their help in the determination of particle characteristics, in the preparation of SEM micrographs and in thermal analysis. The authors also thank the assistance of János Kovács in the rheological measurements. TVK, US Gypsum Co. and NatureWorks are acknowledged for the donation of raw materials. The research on heterogeneous polymer systems was partly financed by the National Scientific Research Fund of Hungary (OTKA Grant No. K 68748 and F 68579), we appreciate the support very much. One of the authors is indebted also to the János Bolyai Research Scholarship of the Hungarian Academy of Sciences. CIRMAP thanks the Belgian Federal Government Office Policy of Science (SSTC) for general support in the frame of PAI-6/27.

\section{References}

[1] Auras R., Harte B., Selke S.: An overview of polylactides as packaging materials. Macromolecular Bioscience, 4, 835-864 (2004).

DOI: $10.1002 / \mathrm{mabi} .200400043$

[2] Li B., Chen S-C., Qiu Z-C., Yang K-K., Tang S-P., Yu W-J., Wang Y-Z.: Synthesis of poly(lactic acid-b-pdioxanone) block copolymers from ring opening polymerization of p-dioxanone by poly(L-lactic acid) macroinitiators. Polymer Bulletin, 61, 139-146 (2008). DOI: $10.1007 / \mathrm{s} 00289-008-0939-1$

[3] Masayuki H., Yoshiharu K.: Thermomechanical properties of stereoblock poly(lactic acid)s with different PLLA/PDLA block compositions. Polymer, 49, 26562661 (2008). DOI: $10.1016 /$ j.polymer.2008.04.014

[4] Ho C. H., Wang C. H., Lin C. I., Lee Y. D.: Synthesis and characterization of TPO-PLA copolymer and its behavior as compatibilizer for PLA/TPO blends. Polymer, 49, 3902-3910 (2008).

DOI: 10.1016/j.polymer.2008.06.054

[5] Mert O., Doganci E., Erbil H. Y., Demir A. S.: Surface characterization of poly(L-lactic acid)-methoxy poly(ethylene glycol) diblock copolymers by static and dynamic contact angle measurements, FTIR, and ATR-FTIR. Langmuir, 24, 749-757 (2008).

DOI: $10.1021 / 1 \mathrm{la} 701966 \mathrm{~d}$

[6] Södergard A., Stolt M.: Properties of lactic acid based polymers and their correlation with composition. Progress in Polymer Science, 27, 1123-1163 (2002). DOI: $\underline{10.1016 / S 0079-6700(02) 00012-6}$

[7] Koji N., Yoshihiro N., Yuichi O., Tatsuro O.: Impacts of stereoregularity and stereocomplex formation on physicochemical, protein adsorption and cell adhesion behaviors of star-shaped 8-arms poly(ethylene glycol)-poly(lactide) block copolymer films. Polymer, 48, 2649-2658 (2007).

DOI: 10.1016/j.polymer.2007.03.017

[8] Gua S-Y., Zhang K., Ren J., Zhan H.: Melt rheology of polylactide/poly(butylene adipate-co-terephthalate) blends. Carbohydrate Polymers, 74, 79-85 (2008). DOI: 10.1016/j.carbpol.2008.01.017

[9] Rohman G., Laupretre F., Boileau S., Guérin P., Grande D.: Poly(D,L-lactide)/poly(methyl methacrylate) interpenetrating polymer networks: Synthesis, characterization, and use as precursors to porous polymeric materials. Polymer, 48, 7017-7028 (2007). DOI: 10.1016/j.polymer.2007.09.044

[10] Wang N., Zhang X., Ma X., Fang J.: Influence of carbon black on the properties of plasticized poly(lactic acid) composites. Polymer Degradation and Stability, 93, 1044-1052 (2008). DOI: $10.1016 /$ j.polymdegradstab.2008.03.023 
[11] Paul M-A., Alexandre M., Degée P., Henrist C., Rulmont A., Dubois P.: New nanocomposite materials based on plasticized poly(L-lactide) and organo-modified montmorillonites: Thermal and morphological study. Polymer, 44, 443-450 (2003).

DOI: $10.1016 / \mathrm{S} 0032-3861(02) 00778-4$

[12] Bhat G. S., Gulgunje P., Desai K.: Development of structure and properties during thermal calendering of polylactic acid (PLA) fiber webs. Express Polymer Letters, 2, 49-56 (2008).

DOI: 10.3144/expresspolymlett.2008.7

[13] Pluta M., Jeszka J. K., Boiteux G.: Polylactide/montmorillonite nanocomposites: Structure, dielectric, viscoelastic and thermal properties. European Polymer Journal, 43, 2819-2835 (2007). DOI: 10.1016/j.eurpolymj.2007.04.009

[14] Gorna K., Hund M., Vucak M., Gröhn F., Wegner G.: Amorphous calcium carbonate in form of spherical nanosized particles and its application as fillers for polymers. Materials Science and Engineering A, 477, 217-225 (2008).

DOI: 10.1016/j.msea.2007.05.045

[15] Bleach N. C., Nazhat S. N., Tanner K. E., Kellomäki M., Törmälä P.: Effect of filler content on mechanical and dynamic mechanical properties of particulate biphasic calcium phosphate-polylactide composites. Biomaterials, 23, 1579-1585 (2002). DOI: $\underline{10.1016 / \mathrm{S} 0142-9612(01) 00283-6}$

[16] Bax B., Müssig J.: Impact and tensile properties of PLA/cordenka and PLA/flax composites. Composites Science and Technology, 68, 1601-1607 (2008). DOI: $10.1016 /$ j.compscitech.2008.01.004

[17] Kuan C. F., Kuan H. C., Ma C. M., Chen C. H.: Mechanical and electrical properties of multi-wall carbon nanotube/poly(lactic acid) composites. Journal of Physics and Chemistry of Solids, 69, 1395-1398 (2008). DOI: $10.1016 /$ j.jpcs.2007.10.060

[18] Murariu M., Ferreira A. D., Degee P., Alexandre M., Dubois P.: Polylactide compositions. Part 1: Effect of filler content and size on mechanical properties of PLA/calcium sulfate composites. Polymer, 48, 26132618 (2007). DOI: 10.1016/j.polymer.2007.02.067

[19] Pluta M., Murariu M., Ferreira A. D., Alexandre M., Galeski A., Dubois P.: Polylactide compositions. II. Correlation between morphology and main properties of PLA/calcium sulfate composites. Journal of Polymer Science Part B: Polymer Physics, 45, 2770-2780 (2007).

DOI: $10.1002 /$ polb.21277

[20] Sobkowicz M. J., Feaver J. L., Dorgan J. R.: Clean and green bioplastic composites: Comparison of calcium sulfate and carbon nanospheres in polylactide composites. Clean- Soil, Air, Water, 36, 706-713 (2008). DOI: $\underline{10.1002 / \text { clen.200800076 }}$
[21] Murariu M., Ferreira A. D., Pluta M., Bonnaud L., Alexandre M., Dubois P.: Polylactide (PLA)-CaSO 4 composites toughened with low molecular weight and polymeric ester-like plasticizers and related performances. European Polymer Journal, 44, 3842-3852 (2008). DOI: $10.1016 /$ j.eurpolymj.2008.07.055

[22] Mishra S., Shimpi N. G.: Effect of the variation in the weight percentage of the loading and the reduction in the nanosizes of $\mathrm{CaSO}_{4}$ on the mechanical and thermal properties of styrene-butadiene rubber. Journal of Applied Polymer Science, 104, 2018-2026 (2007). DOI: $10.1002 /$ app. 25910

[23] Vollenberg P. H. T.: The mechanical behaviour of particle filled thermoplastics. PhD Thesis, Eindhoven University of Technology, Eindhoven (1987).

[24] Nicolais L. Narkis M.: Stress-strain behavior of styrene-acrylonitrile/glass bead composites in the glassy region. Polymer Engineering and Science, 11, 194-199 (1971). DOI: 10.1002/pen.760110305

[25] Demjén Z., Pukánszky B., Nagy J.: Evaluation of interfacial interaction in polypropylene/surface treated $\mathrm{CaCO}_{3}$ composites. Composites Part A: Applied Science and Manufacturing, 29, 323-329 (1998). DOI: $\underline{10.1016 / \mathrm{S} 1359-835 \mathrm{X}(97) 00032-8}$

[26] Fekete E., Pukánszky B., Tóth A., Bertóti I.: Surface modification and characterization of particulate mineral fillers. Journal of Colloid Interface Science, 135, 200-208 (1990).

DOI: $10.1016 / 0021-9797(90) 90300-\mathrm{D}$

[27] Pukánszky B., Fekete E.: Adhesion and surface modification. in 'Advances in Polymer Science, Mineral Fillers in Thermoplastics I' (ed.: Jancar J.) Springer, Berlin, Vol. 139, 109-153 (1999).

DOI: $10.1007 / 3-540-69220-7$

[28] Papirer E., Schultz J., Turchi C.: Surface properties of a calcium carbonate filler treated with stearic acid. European Polymer Journal, 20, 1155-1158 (1984). DOI: $10.1016 / 0014-3057(84) 90181-2$

[29] Móczó J., Fekete E., Pukánszky B.: Adsorption of surfactants on $\mathrm{CaCO}_{3}$ and its effect on surface free energy. Progress in Colloid and Polymer Science, 125, 134-141 (2004). DOI: $\underline{10.1007 / \mathrm{b} 13435}$

[30] Renner K., Yang M. S., Móczó J., Choi H. J., Pukánszky B.: Analysis of the debonding process in polypropylene model composites. European Polymer Journal, 41, 2520-2529 (2005). DOI: 10.1016/j.eurpolymj.2005.05.025

[31] Fekete E., Pukánszky B.: Surface coverage and its determination: Role of acid-base interactions in the surface treatment of mineral fillers. Journal of Colloid and Interface Science, 194, 269-275 (1997). DOI: $10.1006 /$ jcis. 1997.5118 
[32] Fekete E., Móczó J., Pukánszky B.: Determination of the surface characteristics of particulate fillers by linear IGC: A critical approach. Journal of Colloid and Interface Science, 269, 143-152 (2004). DOI: $10.1016 / \mathrm{S} 0021-9797(03) 00719-7$

[33] Pukánszky B., Fekete E.: Aggregation tendency of particulate fillers: Determination and consequences. Polymer and Polymer Composites, 6, 313-322 (1998).

[34] Kiss A., Fekete E., Pukánszky B.: Aggregation of $\mathrm{CaCO}_{3}$ particles in PP composites: Effect of surface coating. Composite Science and Technology, 67, 1574-1583 (2007).

DOI: 10.1016/j.compscitech.2006.07.010

[35] Móczó J., Fekete E., László K., Pukánszky B.: Aggregation of particulate fillers: Factors, determination, properties. Macromolecular Symposia, 194, 111-124 (2003).

DOI: $10.1002 /$ masy.200390071

[36] Pukánszky B., Turcsányi B., Tüdős F.: Effect of interfacial interaction on the tensile yield stress of polymer composites. in 'Interfaces in Polymer, Ceramic, and Metal Matrix Composites' (ed.: Ishida H.) Elsevier, New York, 467-477 (1988).
[37] Pukánszky B.: Influence of interface interaction on the ultimate tensile properties of polymer composites. Composites, 21, 255-262 (1990). DOI: 10.1016/0010-4361(90)90240-W

[38] Dányádi L., Renner K., Móczó J., Pukánszky B.: Wood flour filled PP composites: Interfacial adhesion and micromechanical deformations. Polymer Engineering and Science, 47, 1246-1255 (2007).

DOI: $10.1002 /$ pen. 20768

[39] Vörös G., Fekete E., Pukánszky B.: An interphase with changing properties and the mechanism of deformation in particulate filled polymers. Journal of Adhesion, 64, 229-250 (1997).

DOI: $10.1080 / 00218469708010541$

[40] Móczó J., Fekete E., Pukánszky B.: Acid-base interactions and interphase formation in particulate filled polymers. Journal of Adhesion, 78, 861-875 (2002). DOI: $\underline{10.1080 / 00218460214099}$ 